\title{
Model of Capacity Demand under uncertain Weather
}

\author{
C. J. Wallnerström, J. Setréus, P. Hilber \\ School of Electrical Engineering \\ $\mathrm{KTH}$ - Royal Institute of Technology \\ Stockholm, Sweden \\ cjw@kth.se,jsetreus@kth.se,hilber@kth.se
}

\author{
F. Tong \\ NorthWest Electric Power Design \\ Institute \\ Xi'an, China \\ tongfan@nwepdi.com
}

\author{
L. Bertling \\ Division of Electric Power Engineering \\ Chalmers University of Technology \\ Gothenburg, Sweden \\ lina.bertling@chalmers.se
}

\begin{abstract}
Load forecasting is important in the operation of power systems. The characteristics of the electrical energy consumption are analyzed and its variation as an effect of several weather parameters is studied. Based on historical weather and consumption data received from a distribution system operator (DSO), numerical models of load forecasting are suggested according to electrical power consumption and on daily peak power respectively. Two linear regression models are presented: simple linear regression (SLR) with one input variable (temperature) and multiple linear regressions (MLR) with several input variables. The models are validated with historical data from other years. For daily peak power demand a MLR model has the lowest error, but for prediction of energy demand a SLR model is more accurate.
\end{abstract}

Keywords-component; load Forecasting; linear regression; energy consumtion, climate, electrical distribution systems; risk management;weather vulnerabilit.y

\section{NOMENCLATURE}

$\mathrm{T} \quad$ temperature in degree Celsius $\left({ }^{\circ} \mathrm{C}\right)$

$\mathrm{T}_{\mathrm{a}} \quad$ daily average temperature $\left({ }^{\circ} \mathrm{C}\right)$

$\mathrm{V}_{\mathrm{w} \mathrm{s}} \quad$ wind speed $(\mathrm{m} / \mathrm{s})$

$\mathrm{V}_{\mathrm{w} \mathrm{d}} \quad$ wind direction $\left(^{\circ}\right)$

$\mathrm{A}_{\text {cloud }} \quad$ cloud cover (scale: $1-8,1=\mathrm{min}$ )

$\mathrm{R}_{\mathrm{s} r} \quad$ sun radiation $\left(\mathrm{W} / \mathrm{m}^{2}\right)$

$\mathrm{E}_{\mathrm{i}} \quad$ energy demand in hour $i(\mathrm{MWh})$

$\mathrm{P} \quad$ power $(\mathrm{MWh} / \mathrm{h})$

$\mathrm{P}_{\text {peak }} \quad$ peak power in $24 \mathrm{hrs}(\mathrm{MWh} / \mathrm{h})$

$\alpha_{i} \beta_{i} \quad$ regression coefficients

\section{INTRODUCTION}

The results presented in this paper are based on a Master of Science thesis [1] performed at the Royal Institute of Technology (KTH).

System load forecasting is widely used in different areas since it provides knowledge of probable future power system states [2] [3]. The forecast period depends on the application and change from hour or day for short-term forecast [4] to week and year for medium [5] and long-term forecast. The short-term forecast is needed for control and scheduling of power systems, and also as input to load flow studies or contingency analyses. The medium-term forecast is used in annual maintenance scheduling and operational planning studies and the long-term forecast is required to determine the capacity [6].
Different kinds of aspects such as the customer composition, the price of electricity, people's daily behaviors and weather conditions will affect the power consumption [7]. This paper mainly focuses on how the weather conditions affect the change of power consumption and identify numerical relationships for practical prediction purpose. The weather parameters used are temperature, wind (speed and direction), cloud cover and sun radiation. The main reason by the DSO to initiate this project was to develop a tool for predicting of future peak power when planning for new investments [1].

Ekerö is a Swedish municipality in the Stockholm area consisting of several islands on the lake Mälaren. The municipality consists of both urban and rural areas and greenhouses are a large industry in this region [1]. The electrical DSO is Ekerö Energi, which is partly owned by Fortum Distribution.

\section{MODELING APPROACH}

Three cases of the power demand were identified by the DSO as especially important to model and predict: (1) Energy demand $\mathrm{E}_{\mathrm{i}}(\mathrm{MWh})$ for each hour $i$, (2) Annual energy demand $\mathrm{E}_{\text {total }}(\mathrm{MWh})$, (3) Daily peak power $\mathrm{P}_{\text {peak }}(\mathrm{MW})$ in winter.

The power system has to handle the peak load according to security and reliability [8]. Therefore, it is interesting to study the highest load in winter more in detail, which includes November-March in this report.

\section{INPUT DATA}

In this section input data for the study is presented. Hourly power demand and weather parameters are received for the period 2003 to 2005.

\section{A. Weather Data for Ekerö System}

Historical weather data was received from SMHI (Swedish Meteorological and hydrological Institute), measured at Bromma airport [1], situated (as closest) $\sim 3 \mathrm{~km}$ from Ekerö municipality.

\section{B. Power Demand Data}

There are $\sim 12700$ costumers, a consumption of $\sim 300000$ $\mathrm{MWh} / \mathrm{year}$ and $1270 \mathrm{~km}$ lines and cables in the studied distribution system, situated at a land area of $216 \mathrm{~km}^{2}$ [1]. The main type of customers is people who live in detached houses which are reflected in characteristic of the system. 


\section{CORRELATION OF INPUT DATA}

\section{A. Power Demand vs Outdoor Temperature}

Figure 1 shows the total power demand for the period 2003 to 2005. The power demand is highest in the winter, mostly depending on heating. The peak load of the period is 77 $\mathrm{MWh} / \mathrm{h}$ occurred in January 2003 corresponding to a temperature of $-24^{\circ} \mathrm{C}$, which also was the lowest temperature.

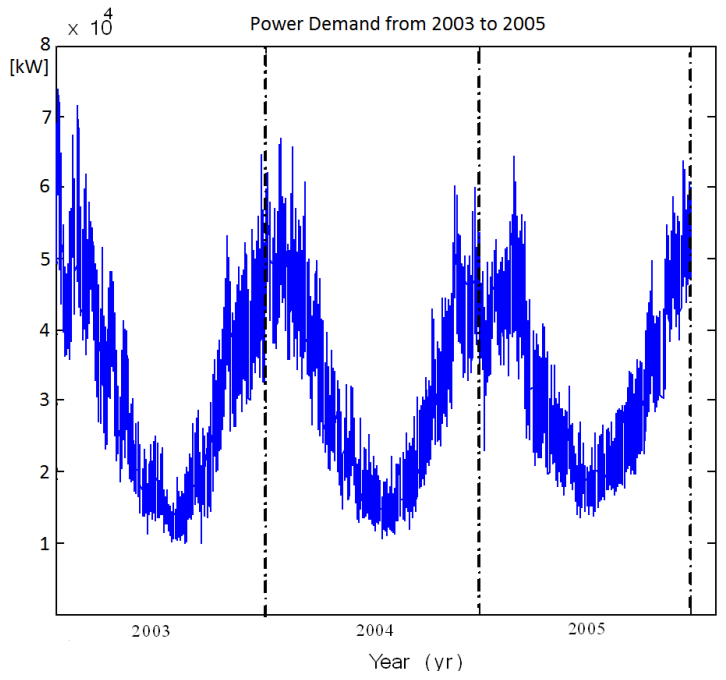

Figure 1 Total power demand in Ekerö during 2003-2005.

\section{B. Power Demand vs Human Activities}

Power utilization is essentially driven by human activity, which can give differences in the power consumption between workday and holiday; weekday and weekend; day and night.

\section{1) Weekdays \& Weekend}

Figure 2 shows a comparison of the average daily power demand between weekdays and weekends during 2003-2004. There are only minor differences and there is not necessary to consider weekdays vs. weekends in the modeling.

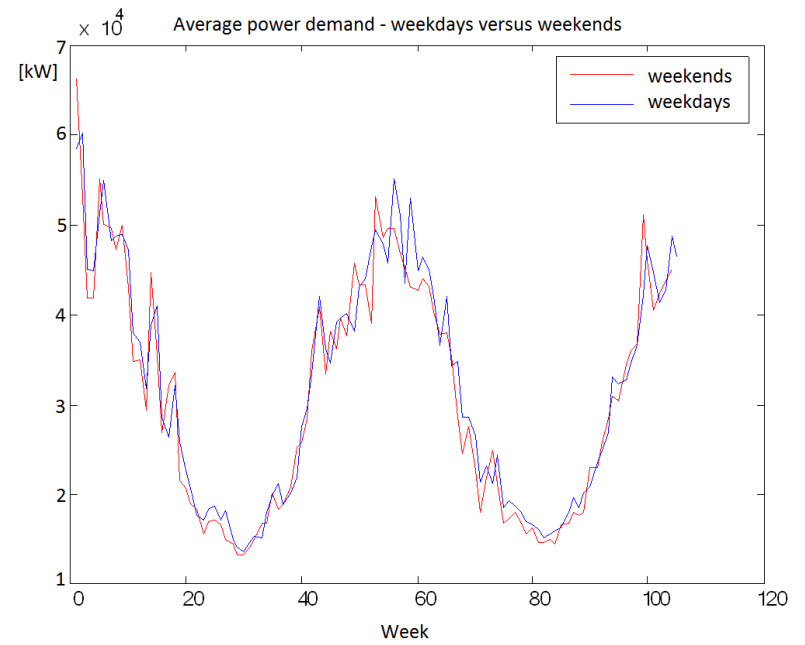

Figure 2 Average power demand for weekdays/weekends.

\section{2) Holiday}

The electricity consumption of industries (greenhouses excluded) is strongly correlated to production. Figure 3 shows that the power consumption is very low during July 20th to August 10th, and the week after Christmas. The power consumption is higher during January and February which is partly explained by the cold weather. Figure 4 illustrates that the power consumption is lower during the weekends.

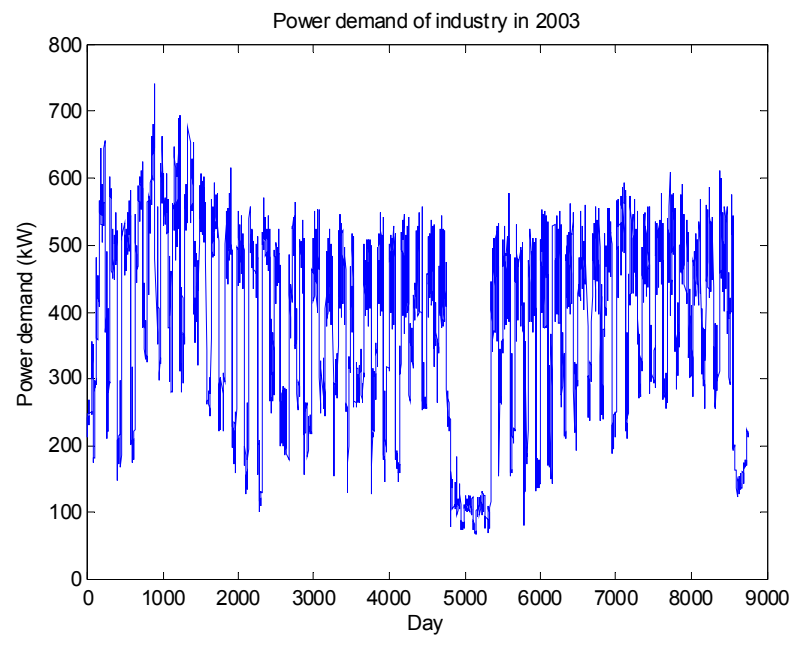

Figure 3 Industry demand during one year.

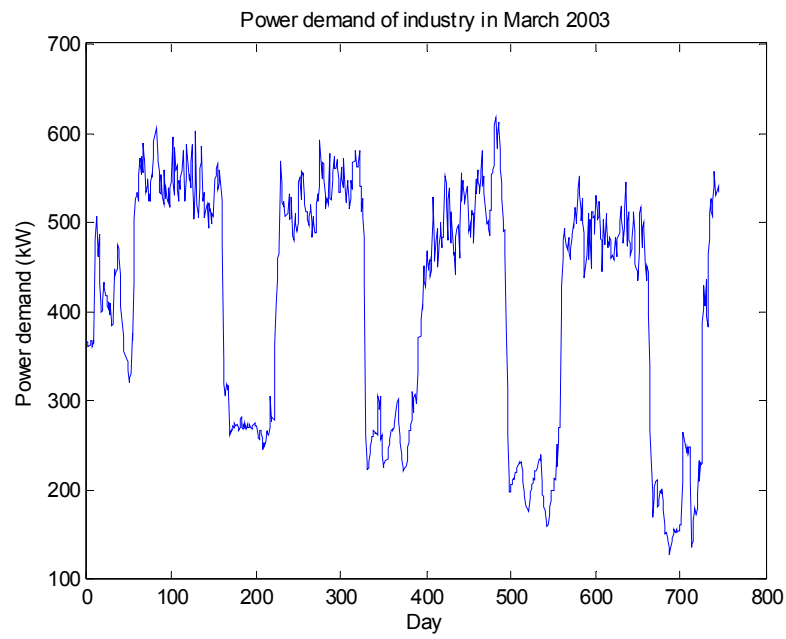

Figure 4 Industry demand during one month

\section{Power Demand vs Solar Radiation}

Within the Ekerö system there are a large proportion of greenhouse companies whose power demand stronger depends on the sun radiation compared with other customers since it is necessary to provide the plants with artificial sun light during their growth.

Figure 5 shows the power demand and the sun radiation $\left(\mathrm{W} / \mathrm{m}^{2}\right)$ for the greenhouse customers in the Ekerö system during one week in the winter (above) and one week in the summer (below). From Figure 5, three properties can be observed. First, that the power demand reaches its top values 
every day, both in summer and winter. During the hours without daylight (although less hours in the summer) the light energy has to be replaced by electricity. Second, the power demand in summer contentiously is close to its top value during all hours without daylight. Consequently, the power demand decreases sharply in the morning. However, the sun radiation is weak and the sun stays much shorter in winter. The third property is that the strength of the sun radiation does not decide how long the minimum power demand needs in greenhouse, the period of minimum load only depends on the time of the sun appearance.
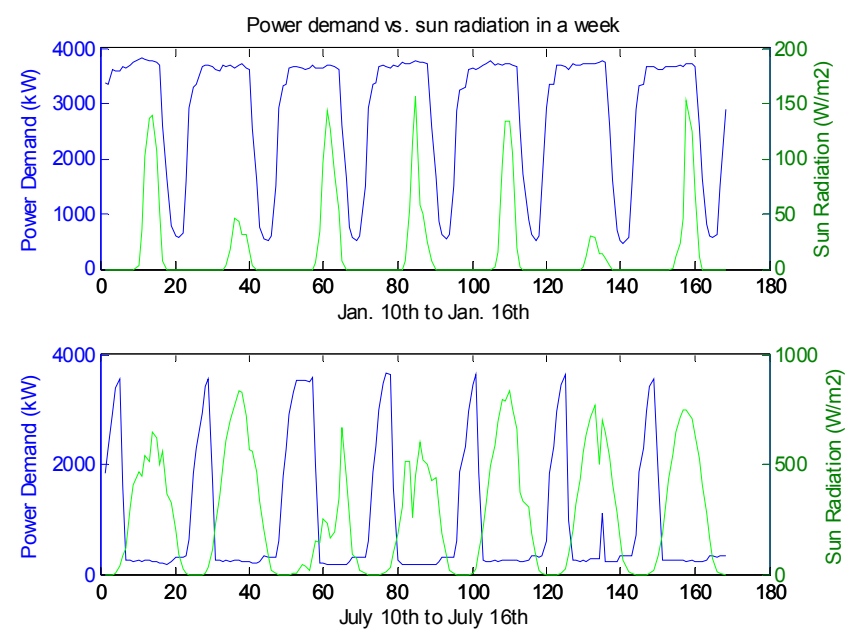

Figure 5 Greenhouses power demand vs. sun radiation.

The comparison between power demand and temperature is shown in Figure 6. In summer, the power demand decreases when the temperature increases, but this correlation is not clear during the winter. This phenomenon is mainly explained by the fact that sun radiation is correlated with temperature (correlation coefficient 0.5217 , see Table 1).
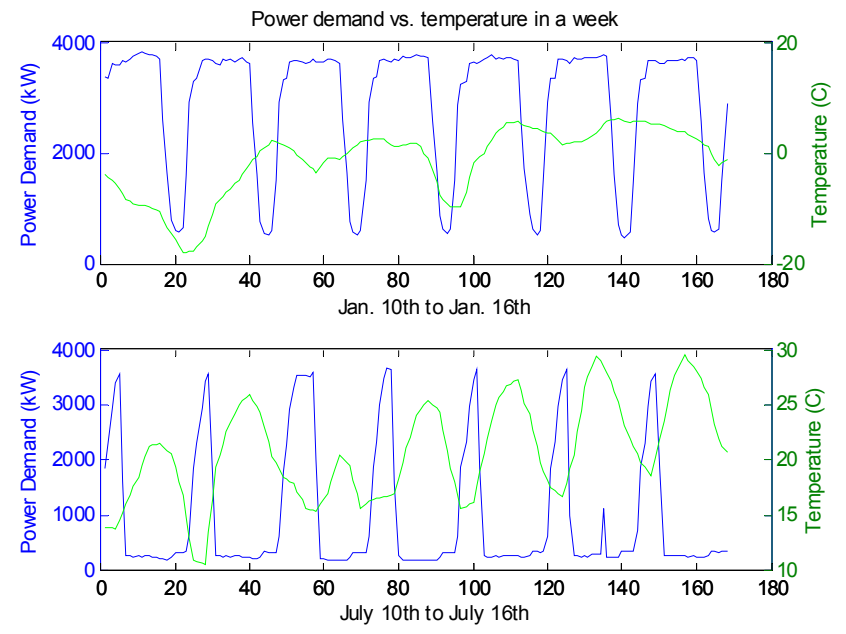

Figure 6 Greenhouses power demand vs. temperature.

\section{Correlation Between Data Parameters}

Table 1 shows a correlation matrix between the observed variables during 2003-2005. Wind conditions and cloudiness have low correlations with the power demand. Temperature has strong correlation with power demand $\mathrm{P}$, which also sun radiation has; however, sun radiation is correlated with temperature, so the causality between sun radiation and power demand for the whole system is uncertain. The parameters in Table 1 are defined in Chapter I (Nomenclature).

Table 1 Correlations between different parameters

\begin{tabular}{|l|c|c|c|c|c|c|}
\hline & $\mathrm{T}$ & $\mathrm{V}_{\mathrm{w} \mathrm{d}}$ & $\mathrm{V}_{\mathrm{w} \mathrm{s}}$ & $\mathrm{A}_{\text {cloud }}$ & $\mathrm{R}_{\mathrm{s} \mathrm{r}}$ & $\mathrm{P}$ \\
\hline $\mathrm{T}$ & 1 & -0.0159 & 0.1326 & -0.0787 & 0.5217 & -0.9033 \\
\hline $\mathrm{V}_{\mathrm{w} \mathrm{d}}$ & -0.0159 & 1 & 0.2685 & -0.0275 & 0.0853 & 0.0629 \\
\hline $\mathrm{V}_{\mathrm{w} \mathrm{s}}$ & 0.1326 & 0.2685 & 1 & 0.1378 & 0.2528 & 0.0247 \\
\hline $\mathrm{A}_{\text {cloud }}$ & -0.0787 & -0.0275 & 0.1378 & 1 & -0.2353 & 0.1607 \\
\hline $\mathrm{R}_{\mathrm{s} \mathrm{r}}$ & 0.5217 & 0.0853 & 0.2528 & -0.2353 & 1 & -0.3888 \\
\hline $\mathrm{P}$ & -0.9033 & 0.0629 & 0.0247 & 0.1607 & -0.3888 & 1 \\
\hline
\end{tabular}

\section{MODEL APPLICATION AND NUMERICAL RESULTS}

Climate and power consumption data for 2003 are used to develop different models of the relationship between power demand and climate. These models are validated by comparing predicted values with the real data for 2004 and 2005.

\section{A. Simple Linear Regression-basic model}

Based on the high correlation coefficient between energy demand and temperature, it is reasonable to find a function using temperature as the dependent variable. The model used is expressed in the form as:

$$
E\left(T_{i}\right)=\alpha_{0}+\sum_{j=1}^{n} \alpha_{j} T_{i}
$$

where $\mathrm{E}_{\mathrm{i}}\left(\mathrm{T}_{\mathrm{i}}\right)$ is the hourly energy demand in the $i^{\text {th }}$ hour of the period, $T_{i}$ is the temperature and $\alpha_{\mathrm{j}}$ are simple linear regression (SLR) coefficients. Three types of power demand have by the DSO been identified as important to predict: hourly and annual energy demand and daily peak power in winter.

\section{1) Houly and annual energy demand with SLR}

The model is based on the hourly power demand and temperature from 2003. Polynomial fit curves can be obtained by different orders in MATLAB. Higher polynomial fit is closer to the real curve, but does on the other hand sharp ends. The $1^{\text {st }}$ to the $10^{\text {th }}$ degree polynomial fit was tested and the $5^{\text {th }}$ degree polynomial fit was chosen as the best "trade-off". The scatter plot of the real power demand versus temperature together with the $5^{\text {th }}$ degree polynomial fit curve is shown in Figure 7. The established function can be written as:

$$
E^{S L R}\left(T_{i}\right)=\alpha_{0}+\alpha_{1} T_{i}+\alpha_{2} T_{i}^{2}+\alpha_{3} T_{i}^{3}+\alpha_{4} T_{i}^{4}+\alpha_{5} T_{i}^{5}
$$

The SLR coefficients (obtained from Matlab) are:

$$
\begin{aligned}
& \alpha_{0}=45736 ; \alpha_{1}=-1745.1 ; \alpha_{2}=-29.123 ; \alpha_{3}=1.8472 ; \\
& \alpha_{4}=0.051824 ; \alpha_{5}=-0.0016493
\end{aligned}
$$




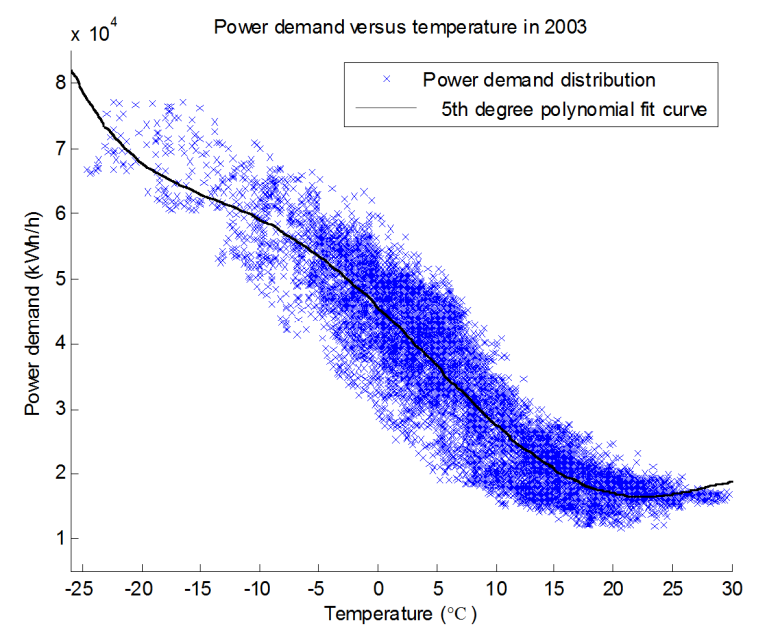

Figure 7 Power demand vs. temperature and $5^{\text {th }}$ degree polynomial fit curve

The annual total demand can be calculated as:

$$
E_{\text {total }}^{S L R}=\sum_{\mathrm{i}=1}^{8760} E^{S L R}\left(T_{i}\right)
$$

\section{2) Daily peak power demand with SLR}

The peak power consumption happens during the winter for the studied system. In this case, the input variable is the average temperature in one day and the output variable is the peak power demand in that day. The resulting polynomial fit curve together with the input data is shown Figure 8 and the relationship between temperature and peak load can be expressed as:

$P_{i_{-} \text {peak }}^{S L R}\left(T_{a}\right)=\alpha_{0}+\alpha_{1} T_{a}+\ldots+\alpha_{5} T_{a}^{5}$,

where $P_{i_{-} \text {peak }}^{\text {SLR }}\left(T_{a}\right)=\max (\mathrm{P} 1, \ldots, \mathrm{P} 24)$ and $T_{a}=\operatorname{mean}(\mathrm{T} 1, \ldots, \mathrm{T} 24)$

The SLR coefficients are:

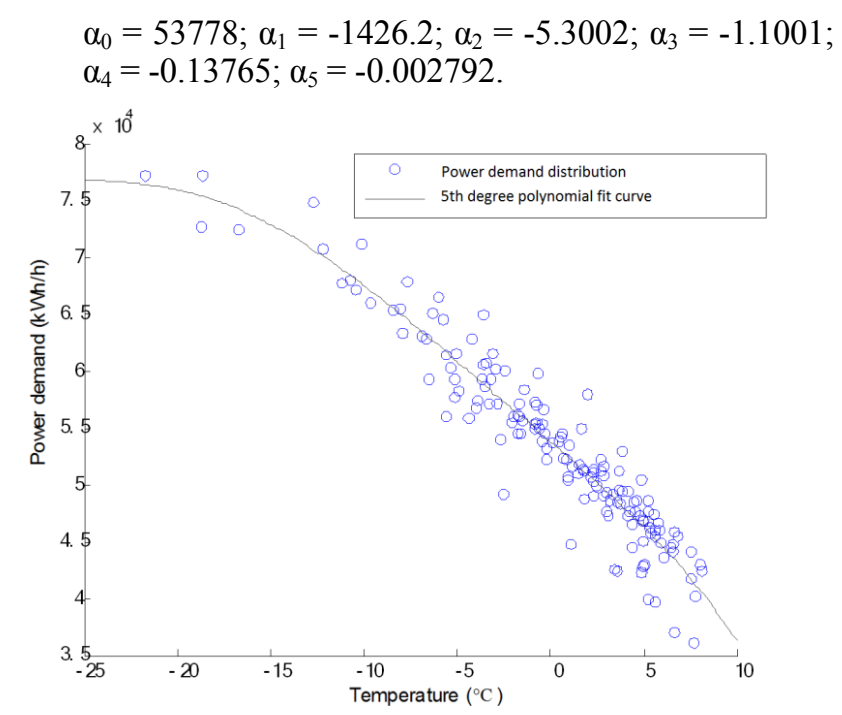

Figure 8 Daily peak power versus daily average temp.

\section{B. Multiple Linear Regression}

Besides the temperature, the power demand is affected by the wind speed, wind direction, cloud cover and sun radiation. A multiple linear regression (MLR) model has been developed and investigated.

\section{1) Houly and annual energy demand with MLR}

The hourly climate data together with the power demand in 2003 are used to establish the model. The model has five input variables. The relationship between climate and power demand can be written as:

$$
\begin{aligned}
& E^{M L R}\left(T_{i}, V_{w_{-} d}^{i}, V_{w_{-} s}^{i}, A_{\text {cloud }}^{i}, R_{s_{-} r}^{i}\right)= \\
& \varepsilon+\beta_{1} T_{i}+\beta_{2} V_{w_{-} d}^{i}+\beta_{3} V_{w_{-} s}^{i}+\beta_{4} A_{\text {cloud }}^{i}+\beta_{5} R_{s_{-} r}^{i}
\end{aligned}
$$

$\mathrm{E}^{\mathrm{MLR}}$ represents the hourly power demand, $\mathrm{T}$ is the temperature, $V_{\mathrm{w}_{-} \mathrm{d}}$ is the wind direction, $\mathrm{V}_{\mathrm{w}_{-} \mathrm{s}}$ is the wind speed, $A_{\text {cloud }}$ is the cloudiness and $\mathrm{R}_{\mathrm{s}_{-}}$is the sun radiation. The coefficients are obtained after data fitting in MATLAB:

$\varepsilon=38680 ; \beta_{1}=-1518 ; \beta_{2}=1.005 ; \beta_{3}=617.3 ; \beta_{4}=581.9 ;$ $\beta_{5}=10.13$.

The annual total demand can be calculated as:

$E_{\text {total }}^{M L R}=\sum_{\mathrm{i}=1}^{8760} E^{M L R}\left(T_{i}, V_{w_{-} d}^{i}, V_{w_{-} s}^{i}, A_{\text {cloud }}^{i}, R_{s_{-} r}^{i}\right)$

\section{2) Daily peak power demand with MLR}

The average values of weather parameters in one day are calculated to apply on this model. The wind direction is neglected since the average value is meaningless in this case:

$P_{i_{-} \text {peak }}^{M L R}\left(T_{a}, V_{w_{-} s_{-} a}, A_{\text {cloud_a } a}, R_{s_{-} r_{-} a}\right)=$
$\varepsilon+\beta_{1} T_{a}+\beta_{2} V_{w_{-} s_{-} a}+\beta_{3} A_{\text {cloud_a }}+\beta_{4} R_{s_{-} r_{-} a}$

$\mathrm{P}_{\mathrm{i} \text { peak }}=$ the maximum hourly power demand in a day, $\mathrm{T}_{\mathrm{a}}$

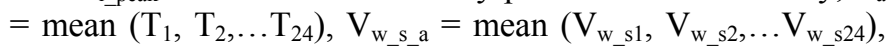

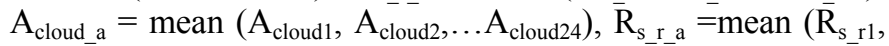
$\left.\mathrm{R}_{\mathrm{s}_{-} \mathrm{r} 2}, \ldots \mathrm{R}_{\mathrm{s}_{-} \mathrm{r} 24}\right)$. The result of execution of the model is: $\varepsilon=55680 ; \beta_{1}=-1310 ; \beta_{2}=385.4 ; \beta_{3}=-368.0 ; \beta_{4}=38.65$.

The coefficients show that the $T_{a}$ has strongest and $R_{s_{-} r_{a}}$ the lowest influence on $\mathrm{P}_{\mathrm{i} \text { _peak }}$.

\section{Validation of models in approach 1}

After the modeling work, the prediction of power demand in 2004 and 2005 has been tested in all models. To compare the accuracy of the models, the mean absolute relative error (MAE) is defined as:

$$
\text { Error }=\frac{\mid \text { actual power demand }- \text { predicted power demand } \mid}{\text { actual power demand }} \times 100 \%
$$

Table 2 shows the MAE obtained from equation (8). The SLR model has lower MAE compared with the other models 
in prediction of hourly power consumption. Average error for SLR is $13.62 \%$ compared with $14.95 \%$ for MLR. In addition, SLR model have very high accuracy to predict yearly total power demand. On the other hand, the MLR model has lower error in the prediction of daily peak load and will be chosen to predict daily peak power demand.

Table 2, error (\%) of load prediction for 2004 and 2005

\begin{tabular}{|l|c|c|c|c|}
\hline \multicolumn{1}{|c|}{ Model } & \multicolumn{2}{|c|}{ A - SLR [error \%] } & \multicolumn{2}{c|}{ B - MLR [error \%] } \\
\hline & 2004 & 2005 & 2004 & 2004 \\
\hline 1. Hourly energy & 13.70 & 13.54 & 15.20 & 14.71 \\
\hline 2. Annual energy & 0.84 & 0.25 & 0.59 & 0.88 \\
\hline 3. Daily peak load & 4.06 & 3.87 & 3.45 & 3.20 \\
\hline
\end{tabular}

\section{Simple Linear Regression - extended model}

The best hourly load forecasting is obtained from the SLR model. However, it still has more than 10\% MAE. In order to decrease the errors, a more detailed model is introduced. To take human behavioral pattern into consideration, the SLR function is spitted into 24 functions, one for each hour in a day. The only difference between this equation (9) and equation (1) is an index " $t$ ", which represents 24 hours in a day. Therefore, there are 24 equations used to predict hourly energy consumption. The $6^{\text {th }}$ degree polynomial fit curve was decided as the best "trade-off":

$$
E^{S L R_{-} t}\left(T_{i}\right)=\alpha_{0}^{t}+\alpha_{1}^{t} T_{i}+\ldots+\alpha_{6}^{t} T_{i}^{6}, t=1,2, \ldots, 24
$$

Most of the MAE (see Table 3) are $<10 \%$, and compared to the previous model, the detailed models improve the accuracy of prediction to $\sim 8 \%$. However, regardless MAE of the proposed models, the uncertainty of the weather forecasts which are needed as input data must been taken into consideration when judging the total accuracy.

Table 3 Error (\%) of prediction for the regression models

\begin{tabular}{|c|c|c|c|c|c|c|c|c|}
\hline \multirow[b]{2}{*}{ Hour } & \multicolumn{2}{|c|}{ Error [\%] } & \multirow[b]{2}{*}{ Hour } & \multicolumn{2}{|c|}{ Error [\%] } & \multirow[b]{2}{*}{ Hour } & \multicolumn{2}{|c|}{ Error [\%] } \\
\hline & 2004 & 2005 & & 2004 & 2005 & & 2004 & 2005 \\
\hline 1 & 11.27 & 11.09 & 9 & 8.44 & 8.58 & 17 & 9.03 & 8.76 \\
\hline 2 & 9.56 & 9.76 & 10 & 7.32 & 7.16 & 18 & 8.54 & 8.55 \\
\hline 3 & 8.8 & 8.86 & 11 & 7.41 & 7.29 & 19 & 8.37 & 7.95 \\
\hline 4 & 9.53 & 9.42 & 12 & 7.45 & 7.58 & 20 & 8.49 & 7.93 \\
\hline 5 & 7.65 & 7.53 & 13 & 7.93 & 7.72 & 21 & 8.77 & 8.12 \\
\hline 6 & 8.97 & 8.08 & 14 & 8.56 & 7.86 & 22 & 8.41 & 8.94 \\
\hline 7 & 11.81 & 10.72 & 15 & 8.9 & 8.24 & 23 & 9.06 & 10.45 \\
\hline 8 & 10.84 & 10.34 & 16 & 9.05 & 8.4 & 24 & 10.15 & 10.96 \\
\hline
\end{tabular}

\section{CONCLUSION}

The characteristics of electrical energy consumption have been analyzed for an electrical distribution system. The power consumption has obviously seasonal properties, e.g. the peak load usually occurs when the temperature goes down. The change of power demand also depends on human behaviors and reaches it bottom value in the night, but does not significant changes between weekdays and weekends. For large greenhouses (an important industry in the studied area), the number of hours with high energy demand strongly is affected by the sun radiation. For other industries the power demand correlates with work activities.

The conclusion is that the consumption in the studied system is strongly correlated with weather parameters, especially temperature. The prediction of energy demand of the total area has been investigated. Linear regression analyses are recommended to forecast the load, which classifying to hourly energy demand, annual total energy demand and daily peak power demand. For daily peak power demand a model using several weather parameters has the lowest error. For prediction of hourly and annual energy demand models using only temperature as input parameter are better.

\section{FUTURE WORK}

Parts of the results from this paper could be valuable input to an ongoing $\mathrm{PhD}$ project [9] with the aim of using risk- and vulnerability analysis as a tool in project- and maintenance planning and includes e.g. a study of the relation between weather states and outages.

\section{ACKNOWLEDGMENT}

The authors would like to express their gratitude to $\mathrm{Mr}$. Olle Hansson at Fortum for his support in the project, and to Anders Sjögren and Stefan Hemström from Ekerö Energi for providing valuable input data. This work is funded by Elforsk AB, the Swedish National Safety Board, FIE and $\mathrm{EKC}^{2}$.

\section{REFERENCES}

[1] T. Fan, "Capacity demand and climate in Ekerö - Development of tool to predict capacity demand under uncertainty of climate effects", M.Sc. Thesis, KTH, Electrical Engeenering, Stockholm, Sweden, April 2007.

[2] M. T. Hagan, S. M. Behr, "The time series approach to short term load forecasting", IEEE Transaction on power systems, August 1987, pp. 785-791

[3] Ibrahim Moghram, Saifur Rahman, "Analysis and evaluation of five short-term load forecasting techniques", IEEE Transactions on power systems, Vol. 4, No.4, October 1989

[4] Alex D. Papalexopoulos, Timothy C. Hesterberg, "A regression-based approach to short-term system load forecasting", Power Industry Computer Application Conference, (PICA '89), 1989

[5] M. S. Owayedh, A. A. Al-Bassam, Z. R. Khan, "Identification of temperature and social events effects on weekly demand behavior", 2000 IEEE, pp2397-2402

[6] Rolf Johansson, "System modeling identification", Englewood Cliffs, N.J. : Prentice Hall, cop. 1993

[7] Lawrence C. Hamilton, "Regression with graphics: a second course in applied statistics", Duxbury Press, 1992

[8] E. H. Barakat, S. A. Al-Rashid, "Long range peak demand forecasting under condition of high growth", IEEE Transaction on power systems, November 1992, pp. 1483-1486

[9] C.J. Wallnerström., "On Risk Management of Electrical Distribution Systems and the Impact of Regulations", Licentiate Thesis, KTH, Sweden, April 2008 